Care: Jurnal Ilmiah Ilmu Kesehatan Vol.8, No.3, 2020, hal 435-446

Tersedia online di https://jurnal.unitri.ac.id/index.php/care

ISSN 2527-8487 (online)

ISSN 2089-4503 (cetak)

\title{
PENAMBAHAN NEUROMUSCULAR TRAINING PROGRAM DALAM MENINGKATKAN PERFORMA FUNGSIONAL ANKLE ATLET SEPAK BOLA LAKI-LAKI DENGAN RIWAYAT ANKLE SPRAIN
}

\author{
Dominggus Ruku Yudit Pramono'), Damayanti Tinduh ${ }^{2)}$, Harlina $^{3)}$ \\ 1),2)3) Program Magister Ilmu Kesehatan Olahraga \\ Fakultas Kedokteran Universitas Airlangga \\ E-mail: yuditmackhz@gmail.com
}

\begin{abstract}
When there is an ankle sprain injury the athlete has decreased functional ability and decreased instability of the ankle joint. One of the actions used to reduce the risk of injury and increase the performance of athletes is by providing a Neuromuscular Training Program (NMT). This study to prove the effect of the provision of the Neuromuscular Training Program on the functional performance. This study used a Randomized Pre Test and Post Test Group Design study design. Respondents of this study were male soccer atbletes, amounting to 18 athletes who met the inclusion criteria, then divided into 2 groups randomly, each group consisted of 9 respondents. The study showed that there were differences in improvement in functional performance after the administration of the Neuromuscular Training Program in male soccer athletes with a history of ankle sprain. In the treatment group shows the results of functional performance (SLHT) with a value of $p=0,000$ indicates a significant effect. Then the results of subjective functional performance measurements using Cumberland Ankle and Instability Tools (CAIT) in the treatment group showed the results of functional performance (CAIT) with a value of $p=0.005$. From the results of the study that there were differences and improves in functional performance after the administration of the Neuromuscular Training Program in male soccer atbletes with a bistory of ankle sprain.
\end{abstract}

Keywords: Ankle sprain; neuromuscular training program; functional performance.

\begin{abstract}
ABSTRAK
Saat terjadi cedera ankle sprain atlet mengalami penurunan kemampuan fungsional dan penurunan instabilitas sendi ankle. Salah satu tindakan yang digunakan untuk menurunkan resiko cedera serta meningkatkan performa atlet adalah dengan memberikan Neuromuscular
\end{abstract}

Cara mengutip: Pramono, D.R. Yudit., Tinduh, Damayanti \& Harlina. (2020). Penambahan Neuromuscular Training Program dalam Meningkatkan Performas Fungsional Ankle Atlet Sepak Bola Laki-laki dengan Riwayat Ankle Sprain. Care:Jurnal Ilmiah Ilmu Kesehatan, 8(3), 435-446 
Training Program (NMT). Tujuan penelitian ini utuk membuktikan pengaruh pemberian Neuromuscular Training Program terhadap performa fungsional atlet sepakbola dengan riwayat Ankle Sprain. Penelitian ini menggunakan rancangan penelitian Randomized Pre Test and Post Test Group Design. Responden penelitian ini adalah atlet sepak bola laki-laki yang berjumlah 18 atlet, yang dibagi menjadi 2 kelompok secara random, masing - masing kelompok berjumlah 9 responden. Penelitian menunjukan bahwa ada perbedaan peningkatan performa fungsional pasca pemberian Neuromuscular Training Program pada atlet sepak bola laki-laki dengan riwayat ankle sprain, Pada kelompok perlakuan menunjukan hasil (SLHT) dengan nilai $\mathrm{p}=0,000$ menunjukkan pengaruh yang bermakna. Kemudian pada hasil pengukuran performa fungsional secara subyektif dengan menggunakan (CAIT) pada kelompok perlakuan menunjukan hasil (CAIT) dengan nilai $\mathrm{p}=0,005$. Dari hasil penelitian bahwa penelitian bahwa pemberian Neuromuscular Training Program pada atlet sepak bola laki-laki dengan riwayat ankle sprain dapat meningkatkan performa fungsional ankle.

Kata Kunci : Ankle Sprain; Neuromuscular Training Program; Performa Fungsional.

\section{PENDAHULUAN}

Olahraga sepak bola adalah olahraga yang mempunyai banyak manfaat untuk kesehatan, akan tetapi juga mempunyai risiko cedera yang tinggi, khususnya pada ekstrimitas bawah (Harry \& Bouwien, 2011). Di Eropa, rata-rata pada pemain sepak bola profesional laki-laki mendapatkan 2 kali cedera setiap satu musim kompetisi. Cidera yang terjadi pada anggota gerak bawah sekitar 60-87 $\%$ (Arundale, Silvers, Logerstedt, Rojas, \& Snyder-Mackler, 2015). Pergelangan kaki (ankle) adalah sendi yang sering mengalami cidera pada olahraga sepak bola. Ankle sprain merupakan cedera yang sering dialami oleh pesepakbola, baik muda maupun dewasa pada atlet laki-laki. Sekitar 85\% dari kejadian sprain pada pergelangan kaki melibatkan ligamentum bagian lateral. Instabilitas pada pergelangan kaki merupakan cedera lanjutan dari sprain pada masa akut yang menyebabkan sindroma yang berlebihan dari jaringan lunak sekitarnya.

Dalam dunia olahraga, sprain pada pergelangan kaki terjadi dalam olahraga kontak fisik, olahraga dalam ruangan, dan olahraga yang menggunakan teknik loncatan dengan frekuensi yang tinggi (Wong \& Hong, 2005). Saat terjadi cedera ankle sprain atlet mengalami penurunan kemampuan fungsional dan penurunan instabilitas sendi ankle. Yang dimana kondisi ini sangat mempengaruhi peforma atlet menjadi menurun (Martin, Davenport, Paulseth, Wukich, \& Godges, 2013). Pada dasarnya tindakan preventif dan rehabilitatif sangat dibutuhkan atlet saat kondisi pasca cidera maupun tidak cidera yang bertujuan untuk menurunkan 
Care: Jurnal Ilmiah Ilmu Kesehatan Vol.8, No.3, 2020, hal 435-446

resiko cidera maupun meningkatkan performa atlet. Mengingat bahwa olahraga sepak bola mempunyai resiko cedera yang tinggi pada ekstrimitas bawah dan mempunyai dampak pada performa atlet maka perlu dilakukan tindakan pencegahan. Salah satu tindakan preventif dan rehabilitatif yang digunakan untuk menurunkan resiko cedera serta meningkatkan performa atlet adalah dengan memberikan Neuromuscular Training Program ( NMT Program ) (Harry \& Bouwien, 2011).

Neuromuscular Training Program merupakan metode latihan yang digunakan oleh atlet dengan memanfaatkan proses sensori informasi dan muscle control yang berkontribusi langsung pada stabilisasi sendi dan pola gerakan (Fischer \& Donald, 2006). Pada dasarnya tindakan preventif dan rehabilitatif sangat dibutuhkan atlet saat kondisi pasca cidera maupun tidak cidera yang bertujuan untuk menurunkan resiko cidera maupun meningkatkan performa atlet. Ada 6 komponen utama yang di rekomendasikan dalam upaya menurunkan risiko cidera yaitu : meningkatkan kekuatan anggota gerak bawah dan kekuatan otot-otot inti punggung bawah serta perut, memberikan latihan plyometric, mengevaluasi teknik yang baik untuk atlet secara berkelanjutan, memberikan dosis latihan yang tepat, meminimalkan peralatan tambahan untuk latihan, dan memberikan latihan keseimbangan yang diikuti oleh warming up dan latihan ketangkasan (Trojian et al., 2017). Program Neuromuscular training ini mempunyai hasil yang signifikan untuk mengurangi resiko cedera pada anggota gerak bawah, selain itu juga untuk mempersiapkan atlet pasca operasi ACL rekonstruksi untuk kembali ke aktivitas olahraga (White, 2014). Sebagai contoh pada atlet olahraga bola tangan penambahan Neuromuscular Training Program pada latihan reguler tiap satu minggu 2 kali selama 6 minggu menunjukkan peningkatan pada stabilitas sendi, menurunkan aligment pada sudut valgus lutut (Fischer \& Donald, 2006).

\section{METODE PENELITIAN}

Jenis penelitian yang dilakukan adalah field experiment. Penelitian ini menggunakan rancangan penelitian Randomized Pre Test and Post Test Control Group Design. Populasi pada penelitian ini adalah seluruh atlet sepak bola profesional di Persebaya Surabaya. Sampel penelitian ini diambil dari populasi tersebut di atas dengan kriteria inklusi yaitu subyek berjenis lakilaki, umur 21-36, IMT 18-24 (kategori 
normal), bersedia menjadi subyek penelitian dengan mengisi informed consent, memiliki riwayat cedera ankle sprain, dinyatakan positif saat dilakukan anterior drawer sign tes dan single leg one tes. Serta bersedia mengikuti protokol selama latihan. Jumlah subyek adalah 18 yang dibagi secara random menjadi 2 kelompok yaitu 9 kelompok perlakuan dan 9 kelompok kontrol. Sebelum penelitian dilakukan semua kelompok masing-masing dilakukan pengambilan data (pretest) performa fungsional untuk data pra penelitian. Setiap subyek dilakukan pengukuran performa fungsional secara secara obyektif dengan single leg hop test (SLHT) dan secara subyektif dengan cumberland ankle and stability (CAIT)tools. Setelah di dapatkan data awal pra penelitian pada masingmasing kelompok lalu dilanjutkan dengan perlakuan pada kelompok perlakuan yang diberikan Neuromusuclar Training Program selama 4 minggu, tiap minggu dilakukan selama 3 kali (senin, rabu dan jumat) saat latihan sepak bola. Pemberian NMT program dilakukan selama 20 menit di awal latihan setelah warming up. Sedangkan untuk kelompok kontrol hanya mendapatkan latihan reguler dari tim pelatih. Setelah waktu 4 minggu sudah terlewati maka masing-masing subyek pada kedua kelompok dilakukan pengambilan data kembali (posttest) dengan melakukan pengukuran performa fungsional secara secara obyektif dengan single leg hop test (SLHT) dan secara subyektif dengan cumberland ankle and stability (CAIT) tools.

Data hasil penelitian dianalisa secara statistik menggunakan bantuan program uji statistic SPSS versi 25. Tahapan analisa data meliputi uji deskriptif digunakan untuk mengetahui sebaran data, Hasil rerata pre dan post performa fungsional single leg hop test (SLHT) dan cumberland ankle and stability tools (CAIT). Kemudian dilanjutkan dengan uji normalitas menggunakan Shapiro-Wilk untuk mengetahui distribusi data tersebut normal, kemudian dilakukan uji homogenitas dengan uji levene test. Setelah itu dilanjutkan uji beda mengunakan paired t-test untuk mengetahui hasil uji dari pre dan post performa fungsional single leg hop test (SLHT) baik dari kelompok perlakuan maupun kelompok kontrol. Setelah itu pada performa fungsional cumberland ankle and stability tools (CAIT) baik dari kelompok perlakuan maupun kelompok kontrol karena data yang di dapatkan adalah data ordinal maka dilakukan uji Wilcoxon Sign Rank Test. Selanjutnya untuk mengetahui perbedaan pada kedua 
Care: Jurnal Ilmiah Ilmu Kesehatan Vol.8, No.3, 2020, hal 435-446

kelompok maka dilakukan uji independent $t$ test pada performa fungsional single leg hop test (SLHT), sedangkan pada pada performa fungsional cumberland ankle and stability tools (CAIT) dilakukan uji Mann Whithney oleh karena skala data yang digunakan adalah ordinal.

\section{HASIL}

Analisis deskriptif dilakukan untuk mengetahui sebaran data variabel usia, berat badan, tinggi badan, IMT sebagai variabel kendali dan data variabel tergantung yaitu performa fungsional. Hasil analisis deskriptif berupa rerata dari simpangan baku data usia, berat badan, tinggi badan, IMT subjek penelitian dalam penelitian ini dapat dilihat pada tabel 1.

Tabel 1. Analisa Deskriptif Usia, Berat Badan, Tinggi Badan, IMT Subjek Penelitian

\begin{tabular}{ccc}
\hline Variabel & \multicolumn{2}{c}{ Rerata \pm SD } \\
\cline { 2 - 3 } & $\begin{array}{c}\text { Kelompok } \\
\text { perlakuan }\end{array}$ & $\begin{array}{c}\text { Kelompok } \\
\text { kontrol }\end{array}$ \\
\hline Usia (th) & $26,55 \pm 3,92$ & $28,77 \pm 4,05$ \\
Berat & $66,88 \pm 5,90$ & $68,33 \pm 6,40$ \\
badan & & \\
(kg) & & \\
Tinggi & $168,4 \pm 7,07$ & $167,8 \pm 3,62$ \\
badan & & \\
$(\mathrm{cm})$ & & \\
$\mathrm{IMT}$ & $23,14 \pm 2,34$ & $24,23 \pm 2,11$ \\
$\left(\mathrm{~kg} / \mathrm{m}^{2}\right)$ & & \\
\hline
\end{tabular}

Pada Tabel 1 menunjukan data variabel yang terdiri dari usia, berat badan, tinggi badan dan IMT. Untuk hasil rerata dan standar deviasi variabel usia pada kelompok perlakuan adalah 26,55 $\pm 3,92$, sedangkan pada kelompok kontrol 28,77 $\pm 4,05$. Selanjutnya untuk hasil rerata dan standar deviasi variabel berat badan kelompok perlakuan adalah 66,88 $\pm 5,90$, sedangkan pada kelompok kontrol 68,33 \pm 6,40. Pada variabel tinggi badan menunjukan hasil rerata dan standar deviasi yaitu pada kelompok perlakuan 168,4 \pm 7,07 sedangkan pada kelompok kontrol 167,8 \pm 3,62. Selanjutnya untuk hasil rerata dan standar deviasi variabel IMT kelompok perlakuan 23,14 \pm 2,34 sedangkan pada kelompok kontrol 24,23 $\pm 2,11$.

Dari hasil pemeriksaan terhadap variabel performa fungsional dengan menggunakan Single Leg Hop Test (CAIT) dan pengisian quesioner Cumberland Ankle and Instability Tools (CAIT) yang dilakukan sebelum program latihan (pre test) dan 1 hari setelah program latihan berakhir (post test). Berdasarkan data performa fungsional tersebut maka dapatkan hasil pada kelompok perlakuan dan kelompok kontrol baik sebelum maupun sesudah dilakukan pemberian Neuromuscular Training Program yaitu pada SLHT sebelum perlakuan pada kelompok perlakuan didapatkan rerata

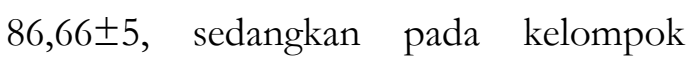


kontrol $86 \pm 5,43$. Kemudian yaitu pada SLHT sesudah perlakuan pada kelompok perlakuan didapatkan rerata $95,22 \pm 2,33$, sedangkan pada kelompok kontrol $88,44 \pm 1,81$.

Tabel 2. Hasil data rerata dan sd Single Leg Hop Test (SLHT)

\begin{tabular}{ccc}
\hline Variabel & \multicolumn{2}{c}{ Rerata \pm SD } \\
\hline & $\begin{array}{c}\text { Kelompok } \\
\text { perlakuan }\end{array}$ & $\begin{array}{c}\text { Kelompok } \\
\text { kontrol }\end{array}$ \\
\hline $\begin{array}{c}\text { SLHT sebelum } \\
\text { perlakuan }\end{array}$ & $86,66 \pm 5$ & $86 \pm 5,43$ \\
\hline $\begin{array}{c}\text { SLHT sesudah } \\
\text { perlakuan }\end{array}$ & $95,22 \pm 2,33$ & $88,44 \pm 1,81$ \\
\hline
\end{tabular}

Pada hasil data performa fungsional dengan pengukuran Cumberland Ankle and Isntability Tools (CAIT) didapatkan data yaitu CAIT sebelum perlakuan pada kelompok perlakuan terdapat 9 subyek mengalami gangguan fungsi dan 1 subyek normal. Sedangkan pada kelompok kontrol terdapat 4 subyek mengalami gangguan fungsi dan 5 subyek normal. Selanjutnya pada CAIT sesudah perlakuan pada kelompok perlakuan terdapat 0 subyek mengalami gangguan fungsi dan 9 subyek normal. Sedangkan pada kelompok kontrol terdapat 4 subyek mengalami gangguan fungsi dan 5 subyek normal.

Setelah data rerata pada kedua kelompok sudah diketahui maka dilanjutkan dengan uji normalitas. Data performa fungsional dari hasil Single Leg Hop Test (SLHT) pada kelompok diuji normalitasnya dengan menggunakan uji Shapiro Wilk jumlah sampel 18. menunjukkan bahwa hasil uji normalitas data menunjukkan nilai p pada variabel performa fungsional (SLHT) sebelum perlakuan adalah $0,278(\mathrm{p}>0,05)$ Sedangkan nilai p pada variabel performa fungsional (SLHT) sesudah perlakuan adalah 0,087 (p>0,05) maka dapat disimpulkan bahwa semua kelompok menunjukan hasil $(\mathrm{p}>0,05)$ yaitu data berdistribusi normal.

Kemudian untuk mengetahui kondisi seluruh kelompok sebelum perlakuan adalah sama, maka perlu dilakukan uji homogenitas. Pengujian homogenitas dapat dilakukan apabila data berdistribusi normal. Pengujian homogenitas menggunakan Lavene test. Berdasarkan uji homogenitas performa fungsional (SLHT) sebelum perlakuan dengan Levene test pada tabel 5.3, nilai $\mathrm{p}=0,959$ ( $\mathrm{p}>0,05)$, dan pada uji homogenitas performa fungsional (SLHT) sesudah perlakuan dengan Levene test pada tabel 5.3, nilai $\mathrm{p}=$ $0,883$ ( $p>0,05)$. Maka dapat disimpulkan bahwa performa fungsional (SLHT) mempunyai varian yang homogen. Untuk mengetahui perbedaan antara kelompok perlakuan dan kelompok kontrol dengan menggunakan Pair T Test. 
Tabel 3. Hasil Uji Pair T Test

\begin{tabular}{lcc}
\hline \multicolumn{1}{c}{ Variabel } & N & Nilai p \\
\hline $\begin{array}{l}\text { Performa Fungsional } \\
\text { dengan Single Leg Hop Test }\end{array}$ & 9 & 0,000 \\
$\begin{array}{l}\text { (SLHT) kelompok } \\
\text { pelakuan }\end{array}$ & & \\
$\begin{array}{l}\text { Performa Fungsional } \\
\text { dengan Single Leg Hop Test }\end{array}$ & 9 & 0,205 \\
(SLHT) kelompok kontrol & & \\
\hline
\end{tabular}

Pada kelompok perlakuan menunjukan hasil dari performa fungsional (SLHT) dengan nilai $\mathrm{p}=0,000(\mathrm{p}<0,05)$ menunjukkan bahwa pemberiam latihan NMT pada kelompok perlakuan berpengaruh secara bermakna terhadap peningkatan performa fungsional yang dapat dilakukan dengan single leg hop test. Sebaliknya pada kelompok kontrol menunjukan hasil dari performa fungsional (SLHT) dengan nilai $\mathrm{p}=0,205$ ( $\mathrm{p}>0,05)$ menunjukkan bahwa pemberian latihan NMT tidak berpengaruh secara bermakna terhadap performa fungsional yang dapat dilakukan dengan single leg hop test. Selanjutnyau untuk mengetahui perbedaan antara kelompok perlakuan dan kelompok kontrol pada skala data ordinal / bertingkat dengan menggunakan Wilcoxon signed rank test.

Berdasarkan hasil pengukuran performa fungsional secara subyektif dengan menggunakan Cumberland Ankle and Instability Tools (CAIT) pada kelompok perlakuan menunjukan hasil dari performa fungsional (CAIT) dengan nilai $\mathrm{p}=0,005(\mathrm{p}<0,05)$ menunjukkan bahwa pada kelompok perlakuan, pemberian Neuromusular Training Program berpengaruh secara bermakna terhadap peningkatan performa fungsional secara subyektif berdasarkan pengukuran CAIT. Hal yang berbeda terjadi pada kelompok kontrol menunjukan hasil dari performa fungsional (CAIT) dengan nilai $\mathrm{p}=0,414$ $(p>0,05)$ yang artinya pada kelompok kontrol, menunjukan bahwa tidak memiliki pengaruh yang bermakna terhadap performa fungsional secara subyektif berdasarkan pengukuran Cumberland Ankle and Instability Tools (CAIT).

Tabel 4. Hasil Uji Wilcoxon signed rank test.

\begin{tabular}{lcc}
\hline \multicolumn{1}{c}{ Variabel } & N & Nilai p \\
\hline Performa Fungsional dengan & & \\
$\begin{array}{l}\text { Cumberland Ankle and } \\
\text { Instability Tools (CAIT) }\end{array}$ & 9 & 0,005 \\
kelompok pelakuan & & \\
Performa dengan Cumberland & & \\
Ankle and Instability Tools & 9 & 0,414 \\
Fungsional (CAIT) \\
kelompok kontrol
\end{tabular}

Setelah masing-masing kelompok di ketahui perbedaannya, maka selanjutnya adalah mengetahui perbedaan dari hasil performa fungsional antara kedua kelompok yaitu kelompok perlakuan dan kelompok kontrol, Maka dilakukan Uji Independent Sample Test pada keuda 
kelompok tersebut. Berdasarkan hasil Uji test tersebut didapatkan hasil yang menunjukan perbedaan signifikan antara kelompok perlakuan dengan kelompok kontrol yang dilakukan pengukuran Single Leg Hop Test (SLHT) didapatkan nilai $\mathrm{p}=$ $0,014(\mathrm{p}<0,05)$ yang artinya menunjukan bahwa ada perbedaan yang signifikan pada performa fungsional antara kelompok perlakuan dengan kelompok kontrol yang dilakukan pengukuran Single Leg Hop Test (SLHT).

Untuk mengetahui perbedaan dari hasil performa fungsional antara kedua kelompok yaitu kelompok perlakuan dan kelompok kontrol. Maka dilakukan Uji Mann Whitney Test pada kedua kelompok tersebut. Berdasarkan hasil uji tes tersebut didapatkan hasil $\mathrm{p}=0,001(\mathrm{p}<0,05)$ yang menunjukan perbedaan signifikan antara kelompok perlakuan dengan kelompok kontrol yang dilakukan pengukuran Cumberland Ankle and Instability Tools (CAIT).

PEMBAHASAN

\section{Peningkatan Performa fungsional dengan Single Leg Hop Test (SLHT) Pasca Pemberian Neuromuscular Training Program pada Atlet Sepak Bola Laki-Laki Dengan Riwayat Ankle Sprain}

Saat terjadi cedera ankle sprain atlet mengalami penurunan kemampuan fungsional dan penurunan instabilitas sendi ankle. Yang dimana kondisi ini sangat mempengaruhi peforma atlet menjadi menurun ( Peterson, 2000 ).Atlet sepak bola yang memiliki riwayat ankle sprain akan memiliki resiko terjadinya gangguan instabilitas. Instabilitas pasca ankle sprain bisa menyebabkan keterbatasan fisik atlet dalam performa berolahraga.

Pada dasarnya tindakan preventif dan rehabilitatif sangat dibutuhkan atlet saat kondisi pasca cidera maupun tidak cidera yang bertujuan untuk menurunkan resiko cidera maupun meningkatkan performa atlet. Salah satu tindakan preventif dan rehabilitatif yang digunakan untuk menurunkan resiko cedera serta meningkatkan performa atlet adalah dengan memberikan Neuromuscular Training Program (Harry \& Bouwien, 2011). Neuromuscular Training Program merupakan metode latihan yang digunakan oleh atlet dengan 
memanfaatkan proses sensori informasi dan muscle controlyang berkontribusi langsung pada stabilisasi sendi dan pola gerakan (Donald, 2006). Program Neuromuscular training ini mempunyai hasil yang signifikan untuk mengurangi resiko cedera pada anggota gerak bawah, selain itu juga untuk mempersiapkan atlet pasca operasi ACL rekonstruksi untuk kembali ke aktivitas olahraga (White, 2014). Pada atlet olahraga bola tangan penambahan Neuromuscular Training Program pada latihan reguler tiap satu minggu 2 kali selama 6 minggu menunjukkan peningkatan pada stabilitas sendi, menurunkan aligment pada sudut valgus lutut (Fischer \& Donald, 2006).

Berdasarkan beberapa penelitian sebelumnya terkait Neuromuscular Training Program untuk anggota gerak bawah. Maka peneliti mencoba mengimplementasikan program tersebut pada pemain sepak bola laki-laki dengan riwayat ankle sprain. Dimana Neuromuscular Training Program diberikan kepada subyek pemain sepak bola laki-laki dalam satu minggu sebanyak 3 kali selama 4 minggu secara signifikan mengalami peningkatan performa fungsional dengan menggunakan Single Leg Hop Test (SLHT) pada kelompok perlakuan. Sedangkan pada kelompok kontrol menunjukan bahwa tidak memiliki pengaruh yang bermakna terhadap performa fungsional yang dapat dilakukan dengan single leg hop test.

Peningkatan Performa fungsional dengan Cumberland Ankle and Instability Tools (CAIT) Pasca Pemberian Neuromuscular Training Program pada Atlet Sepak Bola LakiLaki Dengan Riwayat Ankle Sprain

Secara bersama-sama setelah dilakukan tes performa fungsional secara obyektif pada masing-masing kelompok, baik kelompok perlakuan maupun kelompok kontrol juga dilakukan tes performa fungsional secara subyektif yaitu dengan Cumberland Ankle and Instability Tools (CAIT). CAIT sangat erat kaitannya dengan aktivitas olahraga khususnya pada sepak bola seperti berlari, melompat, berdiri satu kaki dan berputar (Kunugi, Masunari, Yoshida, \& Miyakawa, 2018). Selain digunakan untuk mengevaluasi kondisi Chronic Ankle Instability, Cumberland Ankle and Instability Tools (CAIT) juga dapat digunakan untuk mengevaluasi tingkat performa fungsional dengan kondisi ankle sprain (Doherty, Bleakley, Hertel, Caulfield, \& Ryan, 2016). Pada olahraga sepak bola, sendi ankle merupakan sendi yang sangat berpengaruh dan mendukung pemain 
sepak bola terutama dalam aktifitas menendang secara berulang, perubahan posisi tubuh secara langsung dan pada saat menumpu setelah gerakan melompat menyundul bola (Agel, Evans, Dick, Putukian, \& Marshall, 2007). Maka dari itu peneliti juga melakukan evaluasi terhadap performa fungsional pemain sepak bola secara subyektif. Dimana Neuromuscular Training Program diberikan kepada subyek pemain sepak bola lakilaki dalam satu minggu sebanyak 3 kali selama 4 minggu secara signifikan mengalami peningkatan performa fungsional dengan menggunakan Cumberland Ankle and Instability Tools (CAIT) pada kelompok perlakuan. Sedangkan pada kelompok kontrol menunjukan bahwa tidak memiliki pengaruh yang bermakna terhadap performa fungsional yang dapat dilakukan dengan Cumberland Ankle and Instability Tools (CAIT). Karena pada kelompok kontrol hanya melakukan latihan reguler saja, dimana tidak menyertakan prinsip latihan untuk preventif injury. Hal ini sejalan dengan penelitian sebelumnya tentang pemberian neuromuscular training untuk pencegahan ACL injury pada atlet perempuan (Fischer \& Donald, 2006).

\section{KESIMPULAN}

Terdapat peningkatan performa fungsional atlet sepakbola laki-laki dengan pengukuran metode Single Leg Hop Test (SLHT) sebelum dan sesudah diberikan Neuromusuclar Training Program. Terdapat peningkatan performa fungsional atlet sepakbola laki-laki dengan pengukuran metode Cumberland Ankle and Instability Tools (CAIT) sebelum dan sesudah diberikan Neuromusuclar Training Program. Terdapat perbedaan peningkatan performa fungsional antara kelompok perlakuan dengan kelompok kontrol yang dilakukan pengukuran dengan metode Single Leg Hop Test (SLHT) dan Cumberland Ankle and Instability Tools (CAIT).

\section{SARAN}

1) Hasil penelitian Neuromuscular Training Program bisa di implementasikan tidak hanya pada atlet/tim sepak bola profesional saja tetapi bisa juga di implementasikan pada atlet/tim sepak bola kelompok usia dini sebagai salah satu usaha preventif injury atau menekan angka cedera serta upaya peningkatan performa pada atlet sepak bola.

2) Perlu bekerja sama dalam hal sosialisasi Neuromuscular Training Program sebagai tindakan preventif 
injury kepada pengurus klub, staf kepelatihan dan asosiasi sepak bola di tingkat kabupaten, kota serta provinsi.

3) Pada penelitian berikutnya hendaknya mengelompokkan subyek berdasarkan tinggi badan atlet.

\section{REFERENSI}

Agel, J., Evans, T. A., Dick, R., Putukian, M., \& Marshall, S. W. (2007). Descriptive Epidemiology of Collegiate Men's Soccer Injuries: National Collegiate Athletic Association Injury Surveillance System , 1988 - 1989 Through 2002 - 2003, 42(2), 270-277.

Arundale, A., Silvers, H., Logerstedt, D., Rojas, J., \& Snyder-Mackler, L. (2015). An interval kicking progression for return to soccer following lower extremity injury. International Journal of Sports Physical Therapy, 10(1), 114-127. Retrieved from

http://www.pubmedcentral.nih.gov $/$ articlerender.fogi?artid $=4325295 \& \mathrm{t}$ ool $=$ pmcentrez\&rendertype $=$ abstra $\mathrm{ct}$

Doherty, C., Bleakley, C., Hertel, J., Caulfield, B., \& Ryan, J. (2016). Single - leg drop landing movement strategies in participants with chronic ankle instability compared with lateral ankle sprain " copers ." Knee Surgery, Sports Traumatology, Arthroscopy, 24(4), 1049-1059.

https://doi.org/10.1007/s00167015-3852-9

Donald, V. (2006). Neuromuscular Training to Prevent Anterior Cruciate Ligament Injury in the Female Athlete.

Fischer, D. V., \& Donald, V. (2006). Neuromuscular Training to Prevent
Anterior Cruciate Ligament Injury in the Female Athlete. Strength and Conditioning Journal, 28(5), 44. https://doi.org/10.1519/15334295(2006)28[44:NTTPAC]2.0.CO; 2

Guyton, A. C., \& Hall, J. E. (2014). Textbook of Medical Physiology (12 ed.). Singapore: Elsevier

Harry, C. A., \& Bouwien, C. M. (2011). Neuromuscular Training Improves Knee Kinematics , in Particular in Valgus Aligned. Strength And Conditioning.

Johnson, D. L., \& Mair, S. D. (2006). Clinical Sports Medicine. Clinical Sports Medicine.

https://doi.org/10.1016/B978-0323-02588-1.X5001-5

Kunugi, S., Masunari, A., Yoshida, N., \& Miyakawa, S. (2018). Physical Therapy in Sport Association between Cumberland Ankle Instability Tool score and postural stability in collegiate soccer players with and without functional ankle instability. Physical Therapy in Sport, 32, 29-33. https://doi.org/10.1016/j.ptsp.2018. 03.002

Lin, C.-W. C., Delahunt, E., \& King, E. (2012). Neuromuscular Training for Chronic Ankle Instability. Physical Therapy, 92(8), 987-991. https://doi.org/10.2522/ptj.201103 45

Martin, R. L., Davenport, T. E., Paulseth, S., Wukich, D. K., \& Godges, J. J. (2013). Ankle Stability and Movement Coordination Impairments: Ankle Ligament Sprains. Journal of Orthopaedic \& Sports Physical Therapy, 43(9), A1-A40. https://doi.org/10.2519/jospt.2013. 0305

Trojian, T., Driban, J., Nuti, R., Distefano, L., Root, H., Nistler, C., ... Labella, C. (2017). Osteoarthritis action alliance 
consensus opinion - best practice features of anterior cruciate ligament and lower limb injury prevention programs, $8(9), \quad 726-734$. https://doi.org/10.5312/wjo.v8.i9.7 26

White, K. (2014). The effects of neuromuscular training on the ability to return-to-activity for the ACL reconstructed athlete. Effects of neuromuscular training on the ability to return-to-activity for the ACL reconstructed athlete.

Wong, P., \& Hong, Y. (2005). Soccer injury in the lower extremities, 473483.

https://doi.org/10.1136/bjsm.2004. 015511 